\title{
Vorwort zur vierten Auflage.
}

$D_{\mathrm{B}} \mathrm{B}$ die starken Auflagen dieses Buches sich so schnell folgen, ist ein sicheres Zeichen für seine Beliebtheit. Wie es den älteren Medizinstudierenden deutscher Zunge (und in den Übersetzungen ins Italienische und ins Russische den fremden Fachgenossen) ein unentbehrlicher Berater geworden ist, so wird es auch von praktischen Ärzten mehr und mehr benutzt, wenn sie sich schnell und zuverlässig über den neuesten Stand des Wissens unterrichten wollen. Der Inhalt und die Rezeptformeln sind erbeblich vermehrt und alle Abschnitte im Sinne der Klarheit und Vollständigkeit sorgfültig verbessert.

Rostock, im Herbst 1898.

\section{Der Verfasser.}

